\title{
HETEROGENEITY OF FOREARM METABOLISM WITH SPECIAL REFERENCE TO FREE FATTY ACIDS *
}

\author{
By MARCEL A. BALTZAN, REUBIN ANDRES, GORDON CADER AND \\ KENNETH L. ZIERLER
}

(From the Department of Medicine, The Johns Hopkins University and Hospital, and The Baltimore City Hospitals, Baltimore, Md.)

(Submitted for publication July 27, 1961 ; accepted August 31, 1961)

The metabolism of the forearm of man has been appraised by application of the Fick principle (1). The data were interpreted as indicative of the metabolism of skeletal muscle, because some two-thirds of the bulk of the forearm is skeletal muscle and because approximately 85 per cent of forearm blood flow perfuses skeletal muscle. These data on 14 subjects showed that resting skeletal muscle of the forearm, with the subject in the basal state, consumed oxygen vigorously and that only $7 \pm 7^{1}$ per cent of its $\mathrm{O}_{2}$ uptake could be accounted for by oxidation of glucose abstracted from arterial blood. Because forearm respiratory quotient was $0.80 \pm 0.03$ it was concluded that the major substrate for oxygen consumption by forearm muscles was lipid. Additional subjects have now been studied and a summary of this more extensive experience is as follows: $16 \pm 5$ per cent of $\mathrm{O}_{2}$ uptake can be accounted for by glucose oxidation (43 subjects), and forearm R.Q. is $0.76 \pm 0.02$ (45 subjects). The missing substrate(s) for oxidation can be calculated to be substances which on oxidation give an R.Q. of 0.71 .

It was predicted that the plasma lipid fraction oxidized by muscle would prove to be that fraction of fatty acid transported in intimate association with serum albumin, variously called free fatty acid (FFA), unesterified fatty acids (UFA), or nonesterified fatty acids (NEFA). This fraction

* These studies were aided by Contract Nonr-248(34) (NR 101-241) between the Office of Naval Research, Department of the Navy, and The Johns Hopkins University; and by grants-in-aid from the National Institutes of Health, Department of Health, Education, and Welfare (A-750); and the Muscular Dystrophy Associations of America, Inc. Reproduction in whole or in part is permitted for any purpose of the United States Government.

1 These data and similarly expressed data throughout the paper will always refer to the mean \pm the standard error of the mean. was a likely candidate because $a$ ) it is present in arterial plasma in such quantities that extraction of only 25 per cent of arterial FFA would furnish the missing substrate for the observed $\mathrm{O}_{2}$ uptake of muscle; $b$ ) circulating FFA is known to turn over with extraordinary rapidity, its half-life in plasma being about 2 minutes $(2,3) ; c$ ) other lipid fractions disappear from the plasma of eviscerated animals only very slowly $(4,5)$.

Over a period of 6 years we have failed to obtain direct evidence that this prediction is true. The discrepancy between what seemed likely to be an unimpeachable prediction and valid experimental observation led us to re-examine the basic assumptions which we had applied to study of the forearm of man and to consider the heterogeneity of the forearm tissues and the complexity of its venous drainage.

It is the purpose of this report to present data on the differences in concentration of various metabolites between superficial and deep venous blood from the forearm of man, to verify the metabolic heterogeneity of the forearm, to report the concentrations of FFA in arterial, deep venous and superficial venous blood plasma from the forearm of man, to point out differences in FFA metabolism in males and females, and to show that a quantitative answer to the question, "Does oxidation of FFA account for nearly all the oxygen consumption of resting skeletal muscle in man in the basal state?" cannot be obtained by any of the techniques currently available.

\section{METHODS}

Subjects were volunteers from the medical student, hospital, and university employee population. They were all adults, mostly in their twenties, and included 62 men and 13 women. Since the technique requires catheterization of two forearm veins and an artery, for technical reasons very obese people were not used. All subjects ate nothing after the preceding evening meal and drank 
only water thereafter. They presented themselves to the laboratory at 8:30 a.m. and blood samples were obtained no earlier than 9 a.m., some 15 to 16 hours after the last meal. Catheterization was as described previously (1).

An 18 gage thin-walled Riley needle was threaded upstream into the brachial artery. A 20 gage thin-walled needle was then threaded through the Riley needle thus converting it into a double-lumen needle, with the tip of the inner needle projecting $5 \mathrm{~cm}$ beyond the tip of the outer needle. The lumen of the 20 gage needle was used for the collection of the arterial blood sample; the injection of Evans blue dye was made through the space between the two needles. It is emphasized that every precaution must be taken to assure that arterial samples are collected without imparting any motion to the arterial needle that may stimulate the artery mechanically and so alter blood flow. Venous catheters (9-inch lengths of polyethylene-90 tubing) were inserted downstream. One catheter was passed through the deep communicating vein in the antecubital fossa until its tip was no longer palpable. It was usually passed until its progress was obstructed by a valve and then withdrawn just sufficiently to restore blood flow. Blood obtained from this catheter is called deep venous blood and will be identified by the symbol DV. A second catheter was placed in the largest accessible superficial vein and was always palpable. Blood obtained from this catheter is called superficial venous blood and will be identified by the symbol SV. In nearly every case $\mathrm{DVo}_{2}$ content was obviously less than $\mathrm{SVo}_{2}$ content simply by gross inspection of the color of the blood.

\section{Analytical methods}

1. Glucose. The Nelson procedure (6) was used in experiments $1-9$, the anthrone method (7) in experiments $10-37$, and the glucose oxidase method (8) in experiments 51-76. Glucose analyses on experiments 38-50 were made with the enzymatic method, but are not being reported because the commercial heparin used in the blood-collection syringe in this group of experiments contained phenol as a preservative. It was later found that phenol interferes with the method. The anthrone method gave somewhat higher arterial concentrations than the other two methods but $\mathrm{A}-\mathrm{V}$ differences were the same with all methods. For simplicity all experiments are reported together regardless of method used.

2. Lactic acid. The Barker and Summerson procedure (9) was used in the first 45 experiments and the lactic dehydrogenase-DPN method (10) in the remainder. There was no significant difference in arterial concentration or A-V difference with the two methods and results from all experiments are therefore reported together.

3. Free fatty acids. These were not analyzed in the first 16 experiments. Plasma samples from experiments 17-28 were transported in frozen state to Dr. Robert Gordon at the National Institutes of Health, Bethesda, Md., who kindly performed the analyses by the method described by him (11). Analyses in the remaining experiments were carried out by us using Dole's method
(12). Comparison of the results obtained with the two methods showed no difference in arterial concentration in the two groups of subjects, but A-DV difference was significantly greater $(p<0.05)$ in the initial group. This difference in the two groups is probably not to be attributed to a difference in analytical methods, however, since elimination of a single one of the 33 subjects in the latter group obliterates the significance of the difference in the results obtained by the two methods. Here also, then, data obtained by both methods will be presented together.

4. Potassium. Internal standard flame photometry was used.

5. Oxygen and $\mathrm{CO}_{2}$. Analyses on whole blood were determined by the method of Van Slyke and Neill (13).

6. Blood flow. This was determined by constant injection indicator-dilution method using Evans blue dye (14).

When the arterial needle and venous catheters were in place a constant intra-arterial injection (about $0.1 \mathrm{ml}$ per minute) of a solution of Evans blue dye was started. When blood was not being collected venous catheters were kept patent by slow gravity drip of $0.155 \mathrm{M} \mathrm{NaCl}$; the inner collecting lumen of the intra-arterial needle was kept blood-free by constant power-driven injection of warmed $0.155 \mathrm{M} \mathrm{NaCl}$ at a rate of less than $0.1 \mathrm{ml}$ per minute. A $5-\mathrm{cm}$ sphygmomanometer cuff was placed about the wrist and inflated to at least $200 \mathrm{~mm} \mathrm{Hg}$ to exclude the hand from the circulation. Five minutes later venous infusions were interrupted and blood was allowed to drip freely from the catheters; 45 seconds later the arterial $\mathrm{NaCl}$ infusion was discontinued and free arterial bleeding was permitted. At the beginning of the sixth minute (after 1 minute of venous and $15 \mathrm{sec}-$ onds of arterial flushing) syringes were connected to the venous catheters and arterial needle (through flexible polyethylene tubing) and blood samples were drawn manually and simultaneously at a rate determined by the slowest flowing of the three, usually SV. The dead space of the syringes was prefilled with a solution of heparin and the dead-space volume was precalibrated gravimetrically.

The experiments were generally designed so that three sets of blood samples were obtained from each subject (where a set of blood samples is an arterial, SV and DV sample). Occasionally fewer or more sets of samples were obtained. The time interval from the first to last set of samples averaged 36 minutes (range, 13 to 85 ).

It is essential that the blood be handled expeditiously. The plugged syringes were carried immediately to the laboratory, a few steps away, where a drop of mercury was drawn into each syringe and the blood was mixed by swirling. Blood was then distributed from the syringe into three tubes, two of which were in ice water and one at room temperature $\left(23^{\circ} \mathrm{C}\right)$. Blood in one of the chilled tubes was immediately laked and Somogyi precipitating agents (15) were added; the supernatant was used later for glucose and lactate determinations. The second chilled tube was centrifuged in the cold; the plasma was held for FFA analysis. The third tube was centri- 
TABLE I

Metabolism of glucose, lactate, potassium, and oxygen and blood flow in the forearm*

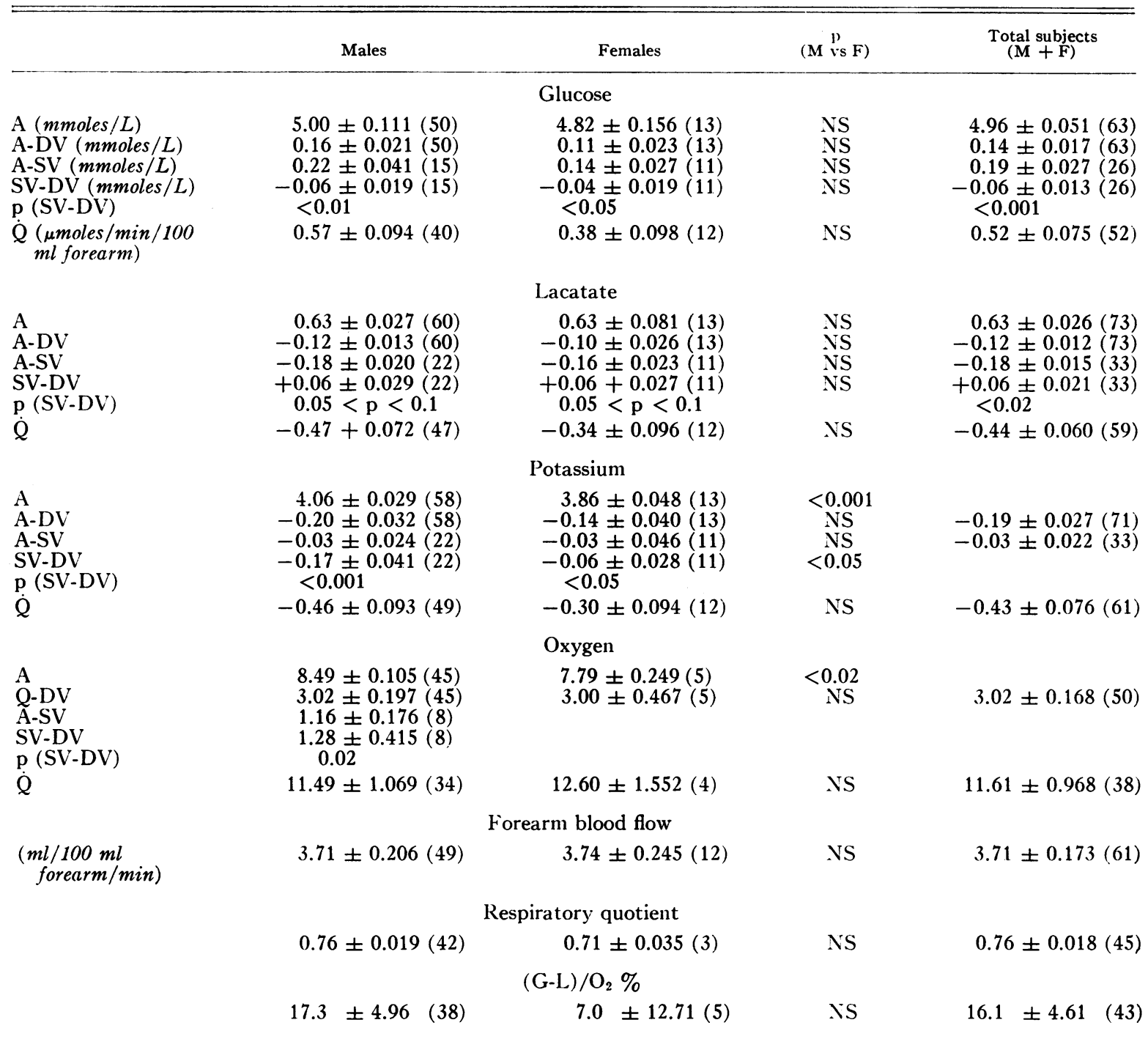

* All values are means $\pm \mathrm{SE}$ of the means. The numbers in parentheses represent the number of subjects studied. There was an average of 3 sets of arterial and venous samples per subject. NS = not significant; that is, $p=0.1$ or more. All values have been calculated to one decimal place beyond those listed in the table for the statistical computations and for derived data; this dropping of the last number is the explanation for what appear to be minor discrepancies at some points; $p$ in the four horizontal lines applies to tests of significance of the difference in concentration of metabolites between superficial and deep veins (SV-DV). Vertical column headed " $p$ (M vs F)" applies to tests of significance of the difference in concentration of metabolites between males and females. $\mathrm{A}=$ concentration of metabolites in arterial blood. A-DV (and A-SV) $=$ the difference in concentration of metabolites between arterial and deep (or superficial) venous blood (except that potassium concentrations were measured in plasma). SV-DV refers only to paired values and is not the difference between mean SV and mean DV for the groups as a whole. $Q=$ net uptake or output, calculated from the product of blood flow and A-DV (except that plasma flow was used for calculation of $Q$ potassium). (G-L)/O $=$ per cent of oxygen consumption accounted for by glucose uptake corrected for lactate production (deep vein). Respiratory quotient calculated from A-DV only.

fuged immediately at room temperature; potassium was determined on this plasma. When gas analyses were performed, part of the blood was kept in the capped syringe which was then placed in ice water while awaiting analysis.

\section{RESULTS}

For each of the parameters of metabolism investigated, results will be presented dealing with the following questions: 
1) Does metabolism of the deep and superficial tissues differ?

2) Is there a sex difference in metabolism?

3) Under these experimental conditions, is the "basal state" a "steady state" or is there a time trend in metabolism during the late morning hours?

Glucose. Arterial concentration, A-DV, and A-SV in both males and females showed no time trends. There was no significant difference in any of these values between males and females. Concentration of glucose in superficial venous blood was significantly less than that in deep venous blood (Table I).

Lactate. There were no significant time trends or sex differences. Both A-DV and A-SV were negative; that is, net lactate production occurred, but in both males and females A-SV was about 50 per cent greater than A-DV (Table I).

Potassium. It has been reported previously that, under the conditions of these experiments, $\mathrm{K}$ appears to be added to venous blood from muscle; that is, concentration of $\mathrm{K}$ in plasma from a deep forearm vein exceeds the arterial plasma $\mathrm{K}$ concentration (16). This was confirmed in the present study: of 73 subjects, deep venous $\mathrm{K}$ exceeded arterial $\mathrm{K}$ in 62 . This was, however, not a consistent finding in the superficial vein; in fact the mean A-SV for both males and females did not differ significantly from zero. The difference in $\mathrm{K}$ concentration in the two veins was definite (Table I). The arterial concentration of $\mathrm{K}$ averaged $0.20 \mathrm{mEq}$ per $\mathrm{L}$ higher in males than in fe- males, a highly significant difference. There was, however, no significant sex difference in A-DV or A-SV. The arterial concentration of $\mathrm{K}$ remained constant during the experimental period. Concentration of $\mathrm{K}$ in plasma from both deep and superficial veins, however, showed a definite tendency to decrease, so that A-DV became less negative with time and A-SV, which was initially only slightly negative on the average, became slightly positive by the end of the experiment. Males and females behaved similarly in this regard.

Oxygen. The somewhat higher arterial oxygen content in males than in females (Table I) is adequately explained by the fact that hematocrits were slightly higher in the male subjects. A-DV was the same in both sexes. Oxygen content in SV was higher than that in DV in all 8 male subjects. There were no time trends in oxygen metabolism over the morning hours.

Free fatty acids. Arterial concentration of FFA was the most labile of the metabolites (Table II). In all 11 female subjects in whom multiple samples were taken there was a fall in concentration during the period of study. The arterial concentration in the male subjects was as likely to rise (15 subjects) as to fall (17 subjects). The initial arterial concentration in the female subjects averaged 50 per cent greater than that in the male subjects. At the end of the experimental period, since FFA concentration in the females fell while that in the males showed no apparent systematic variation, the concentration was only 30 per cent

TABLE II

Plasma FFA concentrations in forearm in basal state *

\begin{tabular}{|c|c|c|c|c|}
\hline & & Arterial & A-DV & $\mathrm{A}-\mathrm{SV}$ \\
\hline Males & $\begin{array}{l}\text { Initial } \\
\text { Final } \\
\text { Change }\end{array}$ & $\begin{array}{c}\text { mmoles } / L \\
0.63 \pm 0.032(35) \\
0.66 \pm 0.031(33) \\
0.02 \pm 0.020(33)\end{array}$ & $\begin{array}{c}\text { mmoles } / L \\
0 \quad \pm 0.019(35) \\
-0.05 \pm 0.028(33) \\
-0.06 \pm 0.020(33) \dagger\end{array}$ & $\begin{array}{c}\text { mmoles } / L \\
-0.13 \pm 0.035(23) \dagger \\
-0.15 \pm 0.028(23) \dagger \\
-0.03 \pm 0.026(23)\end{array}$ \\
\hline Females & $\begin{array}{l}\text { Initial } \\
\text { Final } \\
\text { Change }\end{array}$ & $\begin{array}{c}0.93 \pm 0.090(12) \\
0.86 \pm 0.076(11) \\
-0.10 \pm 0.025(11) \dagger\end{array}$ & $\begin{array}{c}0.10 \pm 0.060(12) \\
0.04 \pm 0.080(11) \\
-0.06 \pm 0.028(11) \dagger\end{array}$ & $\begin{array}{r}-0.15 \pm 0.089(11) \\
-0.05 \pm 0.044(11) \\
0.10 \pm 0.070(11)\end{array}$ \\
\hline $\begin{array}{l}\text { Males vs } \\
\text { females }\end{array}$ & $\begin{array}{l}\text { Initial } \\
\text { Final } \\
\text { Change }\end{array}$ & $\begin{array}{l}0.30 \pm 0.096 \dagger \\
0.20 \pm 0.082 \dagger \\
0.11 \pm 0.032 \dagger\end{array}$ & $\begin{array}{l}0.10 \pm 0.063 \\
0.09 \pm 0.084 \\
0 \quad \pm 0.03\end{array}$ & $\begin{array}{l}0.02 \pm 0.096 \\
0.11 \pm 0.051 \dagger \\
0.13 \pm 0.075 \dagger\end{array}$ \\
\hline
\end{tabular}

* Symbols as in Table I.

+ Refers to those means which differ significantly $(p<0.05)$ from zero, for case of A-V differences, or in which changes were probably not due to chance $(\mathrm{p}<0.05)$. Data are means $\pm \mathrm{SE}$ of means. Numbers of subjects given in parentheses. 


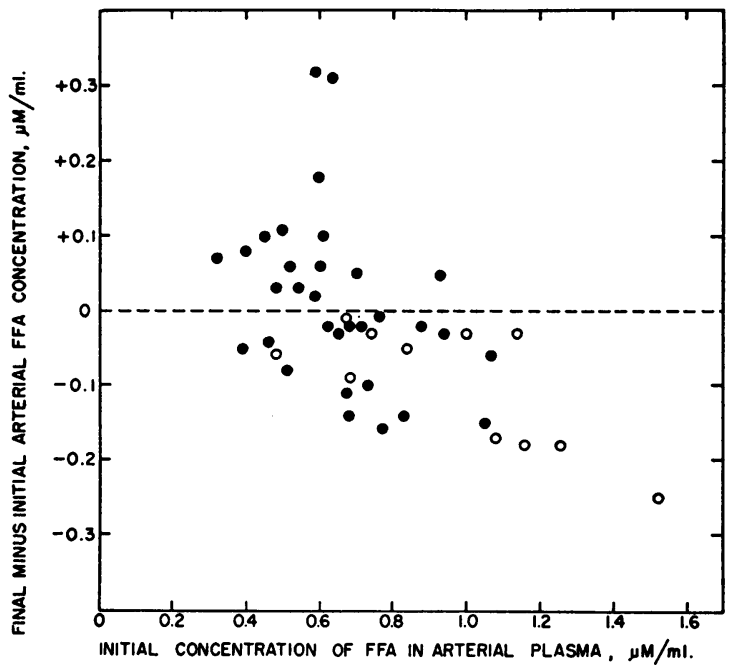

Fig. 1. Relationship Between initial arterial CONCENTRATION OF FFA AND SUBSEQUENT CHANGES IN FFA CONCENTRATION With time. Open circles represent female subjects; closed circles, males.

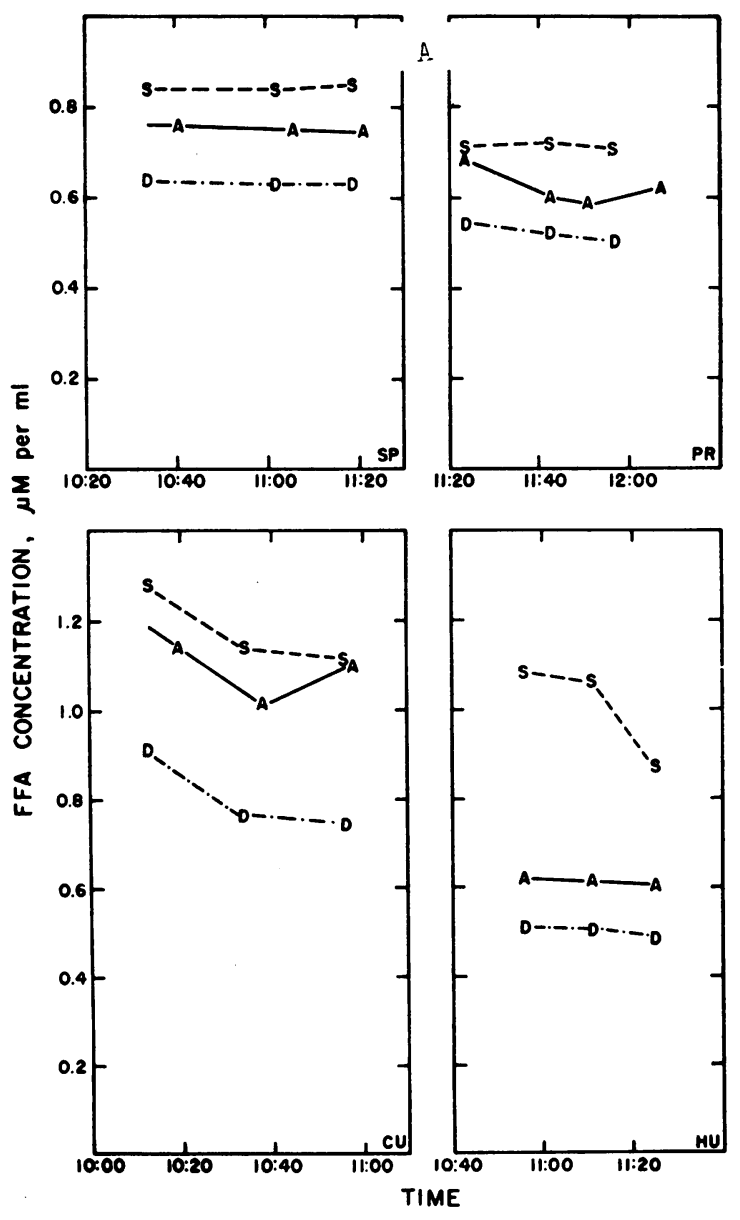

greater, still a significant difference. Because the female subjects had higher arterial concentrations and a distinct downward trend with time, while the males had lower concentrations which tended to rise, the data were further analyzed to see whether the time course of the arterial concentration for the entire group was related to the initial FFA concentration. A strong negative correlation exists (Figure 1). Invariably, large increases in arterial FFA concentration occurred only when the initial concentration was below 0.65 mmole per $\mathrm{L}$; large falls occurred only if the initial concentration exceeded 0.65 .

The expected positive A-DV was not demonstrated for the entire group of subjects, although in some there were consistently large uptakes of

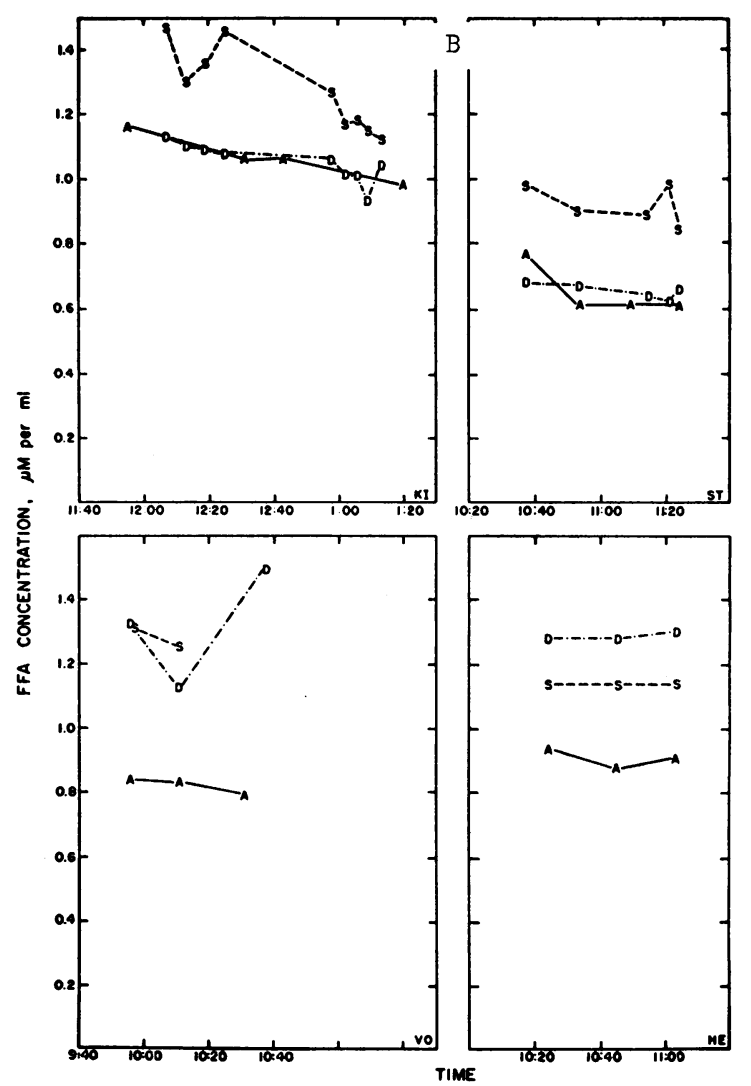

Fig. 2. Concentration of FFA in arterial, deep venous, AND SUPERficial venous plasma. A. Four representative subjects demonstrating uptake of FFA by deep forearm tissues and output from superficial forearm tissues. B. Four subjects demonstrating either no net movement of FFA between arterial and deep venous plasma or output of FFA by deep tissues (see text). Output of FFA by superficial tissues occurs in each of these subjects. 
FFA. Four examples are shown in Figure 2A. Others showed either no A-DV difference (the upper two subjects in Figure 2B) or even negative A-DV difference (the lower two subjects in Figure 2B). These will be commented on below. There was a tendency for the A-DV to become more negative with time in both male and female subjects (Table II). A preliminary report on the A-DV differences in our first 9 subjects was presented by Gordon (17).

The expected output of FFA from superficial tissues was a much more consistent finding : 28 of the 34 subjects had negative A-SV differences (Table II and Figure 2). There was a tendency for the output of FFA to diminish with time in the female subjects, so that by the end of the experimental period the A-SV in the males was more highly negative than in the females, although initially they were essentially the same.

The fraction of the oxygen consumption accounted for by the uptake of FFA can be calculated by assuming that 1 mole of FFA is equivalent to 25 moles of oxygen.

Since $\dot{Q}_{\text {FFA }}=(A-D V)_{\text {FFA }} \times$ plasma flow, and $\dot{\mathrm{Q}}_{\mathrm{O}_{2}}=(\mathrm{A}-\mathrm{DV}) \mathrm{o}_{2} \times$ blood flow; and since plasma

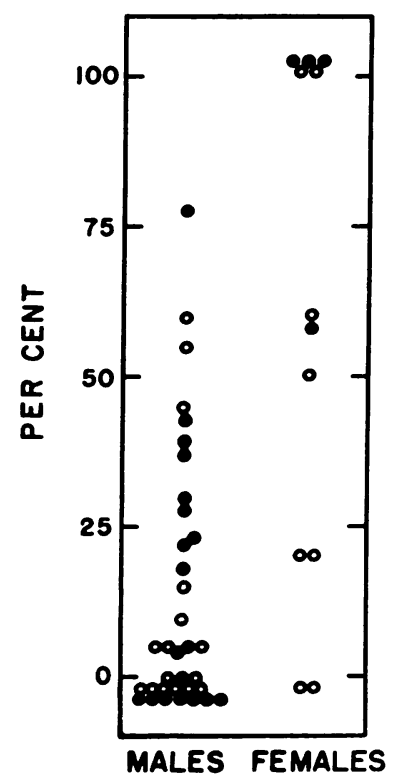

Fig. 3. Per CENT OF OXYGen CONSUMPtion ACCOUNTED FOR BY FFA UPTAKE. Black circles represent those subjects in whom both oxygen and FFA were measured. Open circles represent subjects in whom only FFA was measured; mean value for $(A-D V) \mathrm{O}_{2}$ was used as a rough approximation (see text). flow $=$ blood flow $\times$ plasmacrit, the fraction of $\mathrm{O}_{2}$ uptake accounted for by FFA oxidation, $\mathrm{FFA} / \mathrm{O}_{2}$, can be calculated from:

$$
\frac{\mathrm{FFA}}{\mathrm{O}_{2}}=\frac{(\mathrm{A}-\mathrm{DV})_{\mathrm{FFA}} \times 25 \times \text { plasmacrit }}{(\mathrm{A}-\mathrm{DV}) \mathrm{O}_{2}}
$$

Note that blood flow is not needed for this calculation.

In 23 subjects simultaneous $\mathrm{O}_{2}$ and FFA determinations were made and $\mathrm{FFA} / \mathrm{O}_{2}$ calculated. The closed circles in Figure 3 show that occasionally a major fraction of the oxygen consumption can be accounted for, but in most subjects the role of FFA is apparently minor. In 24 other subjects (the open circles in Figure 3), $\mathrm{O}_{2}$ was not measured; a rough estimate of $\mathrm{FFA} / \mathrm{O}_{2}$ in these subjects can be made by assuming an $\mathrm{A}-\mathrm{DVO}_{2}$ difference of $3 \mathrm{mEq}$ per $\mathrm{L}$ (the mean value in our subjects). FFA appears to account for a larger fraction of $\mathrm{O}_{2}$ uptake in women.

\section{DISCUSSION}

There is nothing novel in the notion that the concentration of certain metabolites is not necessarily identical in all veins draining the forearm. That $\mathrm{O}_{2}$ content may vary widely from vein to vein is so well known as to require no documentation. Monod and co-workers (18) compared the concentrations of $\mathrm{O}_{2}, \mathrm{CO}_{2}$ and lactic acid in a superficial and in a deep vein of the forearm. Their technique differed from ours only in that they did not occlude circulation to the hand. They reported the anticipated fact that $\mathrm{O}_{2}$ content was greater and $\mathrm{CO}_{2}$ content less in superficial than in deep venous blood. Their data differ from ours in that they found lower (though not significantly so) lactic acid concentration in superficial than in deep venous blood. The difference may be owing to the inadequate number of subjects (three) in whom they obtained data on superficial venous lactate concentration and in part to the fact that they do not report SV-DV for individual subjects; that is, they compare mean $\mathrm{SV}$ in 3 subjects to mean DV in 16 subjects.

Superficial venous blood, in our observations, is characterized by a lower glucose and a higher lactate concentration than is deep venous blood. However, the $\mathrm{A}-\mathrm{V}$ differences are such that, both in the tissues drained by the deep vein and in those drained by the superficial vein, about 45 per cent 
of glucose uptake is accounted for by lactate production. Although our data are relatively meager with respect to $\mathrm{A}-\mathrm{SVo}_{2}$ differences, on the average, nearly 60 per cent of $\mathrm{O}_{2}$ uptake by tissues drained by the superficial vein is accounted for by glucose uptake (corrected for lactate production), in contrast to less than 20 per cent for the case of tissues drained by the deep vein.

A report by Butterfield and Schless (19) is unique in that among 8 so-called "control" subjects (but including subjects with obesity, hyperthyroidism, and acromegaly) there were very large FFA A-V differences; so large in fact, that in two of them enough FFA was apparently abstracted to account for several times the mean $\mathrm{O}_{2}$ uptake by our subjects. This report is almost certainly erroneous. Arterial FFA in their subjects was several times the upper limits of normal in all other series, possibly because they kept cannulae patent by intravascular infusion of heparin.

Despite excellent theoretical reasons for anticipating that FFA serves as an important metabolic substrate for forearm tissues, in the majority of cases A-DV was in fact too small to account for a major part of forearm $\mathrm{O}_{2}$ uptake. The failure to show FFA uptake by deep forearm tissues is not to be taken as proof that the role of FFA is minor. In the first place, there is no doubt that FFA is extracted from arterial blood by forearm tissues. This fact is clear from the data of Friedberg and associates (20) who observed that, whether FFA $\mathrm{A}-\mathrm{V}$ difference was positive or negative, the radioactivity of forearm venous blood (site unspecified) was less than that of arterial blood during plateaus of radioactivity in arterial blood in the course of continuous, remote, intravenous infusion of palmitic acid- $\mathrm{C}^{14}$. This is, of course, a purely qualitative observation, and the technique does not permit any decision concerning the magnitude of FFA uptake. In the second place there were, among our subjects, some in whom apparent FFA uptake by tissues drained by the deep vein was adequate to account for a major fraction of $\mathrm{O}_{2}$ uptake. Failure to demonstrate this consistently may depend upon complexities of venous drainage and adipose tissue distribution in the forearm, as suggested by Gordon (17) on the basis of his analyses of our early plasma samples. Since it has now become common to use FFA concentration in antecubital venous plasma as an index of sys- temic metabolism of FFA, a more detailed consideration of these complexities is in order.

Of the tissues composing the forearm, consider only two, adipose tissue and skeletal muscle. For purposes of simplicity consider that arterial blood to the forearm divides into two major paths. One, the superficial bed, supplies subcutaneous adipose tissue. The other, the deep bed, supplies muscle and that adipose tissue which is streaked intimately among muscle bundles. There are known luxuriant intercommunications of superficial and deep veins of the forearm (21). Conceivably, venous effluent from the superficial bed (adipose tissue) may flow, in part, through communicating veins to join the deep venous effluent (largely draining muscle, but including intermuscular adipose tissue). Venous effluent from the deep bed may flow, in part, through communicating veins to join the superficial effluent. A catheter placed in a superficial vein of the forearm may sample, therefore, not only effluent from subcutaneous adipose tissue, but also effluent from muscle and deep adipose tissue. A catheter placed in a deep vein of the forearm may sample not only effluent from muscle and from an uncertain mass of intermuscular adipose tissue, but also an uncertain contamination by superficial venous blood.

The second possibility seems unlikely in view of the recent reports of Roddie, Shepherd and Whelan (22), and Coles, Cooper, Mottram and Occleshaw (23), who showed by several techniques that superficial venous blood does not enter the deep venous system of the forearm unless a pressure cuff above the elbow is inflated to "venous occlusion" pressure, 50 to $70 \mathrm{~mm} \mathrm{Hg}$. Thus, if blood flow were measured by venous occlusion plethysmography, a forced flow of superficial blood into deep veins would be expected. Because the dye-dilution flow method was used in our studies (no venous occlusion), this type of contamination probably did not occur.

In addition to the foregoing anatomical complications there are the following metabolic complexities. First make the assumption that FFA is released from adipose tissue and diffuses into venous blood, and that FFA is taken up by muscle after diffusing from arterial blood. Thus, in the deep forearm tissues when a single vein drains both FFA-producing and FFA-utilizing tissues, the difference in FFA concentration between ar- 
tery and vein is determined by the relative rates of the two processes. An experimental approach to these considerations was attempted in a preparation of the hind limb of the dog (24). In dogs, under pentobarbital anesthesia, all muscles of the left hind limb but the gastrocnemius-plantaris group were removed. The arterial supply to the gastrocnemius-plantaris muscle was isolated so that blood flowed only to this muscle group (and to adipose tissue laced within it). Venous effluent was isolated so that it drained only the gastrocnemius-plantaris group. Superficial fat and major fat deposits between muscle bundles were excised as thoroughly as possible. Despite these precautions, venous FFA concentrations exceeded arterial more than half the time. When net FFA uptake did occur it was far too small to account for the observed $\mathrm{O}_{2}$ consumption. Despite meticulous dissection, much adipose tissue still remained in the preparation; extraction of the muscle with ether-alcohol at the end of the experiment showed about 4 per cent lipid. The pertinence of these experiments to the human studies is open to question. The hind limb preparation has a much higher glucose uptake and R.Q. than has the forearm of man. It seems likely that FFA does not serve as a major substrate in that experimental preparation.

Another factor which cannot be assessed is the possibility of direct diffusion of FFA from deeplying adipose tissue into contiguous muscle through the interstitial fluid without traversing any vascular bed. In this event FFA might serve as a major fuel and be unmeasured by techniques based on the Fick principle.

Sex differences in the metabolism of FFA have not previously been noted. The arterial concentration is much higher in female subjects and, although a fall in concentration does occur with time, it still remains at a higher level. A correlation between FFA concentration and obesity has been noted, but this correlation is present only if extremely obese subjects are included (12). The female subjects of the present series were not obese, but undoubtedly a higher percentage of their body weight was composed of fat than was that of male subjects. Perhaps this is in some way related to the higher basal concentration of FFA in arterial plasma of women.

The explanation for the fall in arterial FFA concentration during the morning hours in some subjects is not known. Stress of the experiment might cause release of epinephrine. This should, however, result in a rise in FFA concentration rather than a fall $(11,12)$, although the excitement during vasopunctures might have produced initially high levels. Epinephrine release, however, should also have caused an elevation of arterial blood glucose and lactate concentration (25) and a fall in arterial potassium (26); but these were all normal in our subjects and furthermore, they showed practically no variations during the morning (all varied by only 1 per cent or less on the average). Nevertheless, the reservation must be held that the FFA response to epinephrine may be a more sensitive index of epinephrine action than is any of the other functions mentioned. The possibility also exists of norepinephrine release, with effects on FFA (27) but with negligible effects on glucose and lactate (28); but this is unproven.

Since there is a "metabolic pattern" for deep and superficial forearm veins, with significant differences in glucose, lactate, potassium, and oxygen as well as in FFA metabolism, it was of interest to examine the total metabolic pattern in those subjects who showed inordinately high negative $(A-D V)_{F F A}$ (as in Figure 2B). This analysis revealed almost always that $\mathrm{A}-\mathrm{V}$ differences of the other metabolites also resembled those to be expected from a superficial vein: positive potassium A-V differences, small oxygen A-V differences, and larger than average glucose and lactate $\mathrm{A}-\mathrm{V}$ differences. Since the introduction of the catheter into the deep forearm tissues is a blind procedure, it seems from the above evidence that occasionally it enters a small vein that drains predominantly tissues which act metabolically like the tissue drained by the superficial veinsi.e., adipose tissue.

The magnitude of the differences in concentration of some metabolites in different forearm veins deserves emphasis. The FFA concentration in one forearm vein may be twice as great as that in another vein (Figure 2A). Clearly, for metabolic studies on FFA involving repeated blood sampling, this variable must be controlled either 1) by sampling through an indwelling needle or catheter whose position is unchanged during the study, or preferably 2) by arterial sampling. 
Studies on glucose, lactate, and potassium metabolism in which great delicacy is required for the measurement of subtle changes will also demand attention to the above strictures.

\section{SUMMARY}

1. Under basal conditions in blood draining chiefly superficial tissues of the forearm, concentrations of glucose and potassium (in plasma) are lower and concentrations of lactate, free fatty acids (FFA) and oxygen are higher than in blood draining chiefly deep tissues of the forearm. The fraction of $\mathrm{O}_{2}$ uptake accounted for by glucose uptake, corrected for lactate production, and complete oxidation of glucose assumed, is much greater in superficial than in deep tissues. Whereas there is net leak of potassium from deep forearm tissues, there is no significant difference between arterial and superficial venous plasma potassium concentration. Superficial tissues, presumably adipose tissues, discharge FFA into venous blood. FFA in deep venous plasma is not significantly different from arterial FFA.

2. Arterial potassium concentration is greater in males, who also show a greater difference in potassium concentration between deep and superficial veins. Females show a much higher arterial FFA concentration, a tendency for FFA concentration to fall with time, and a decreasing output of FFA from superficial tissues.

3 . The changes in arterial concentration of FFA with time are related to the height of the initial values: low concentrations tend to rise and high ones to fall.

4. Owing to anatomical considerations, the Fick principle is not entirely applicable to assessment of FFA metabolism by forearm muscles. It can occasionally be shown that FFA act as major substrates for resting muscle under basal conditions.

\section{ACKNOWLEDGMENT}

We are indebted to those who volunteered for these experiments and to Misses Ellen Rogus and Sara Ann Verplanck, Mrs. Gerda von Ahlefeldt and Mrs. James Cullen for technical assistance.

\section{REFERENCES}

1. Andres, R., Cader, G., and Zierler, K. L. The quantitatively minor role of carbohydrate in oxidative metabolism by skeletal muscle in intact man in the basal state. Measurements of oxygen and glucose uptake and carbon dioxide and lactate production in the forearm. J. clin. Invest. 1956, $35,671$.

2. Laurell, S. Turnover rate of unesterified fatty acids in human plasma. Acta physiol. scand. 1957, 41, 158.

3. Fredrickson, D. S., and Gordon, R. S., Jr. The metabolism of albumin-bound $\mathrm{C}^{\mathbf{1 4}}$-labeled unesterified fatty acids in normal human subjects. J. clin. Invest. 1958, 37, 1504.

4. Havel, R. J., and Fredrickson, D. S. The metabolism of chylomicra. I. The removal of palmitic acid-1-C ${ }^{14}$ labeled chylomicra from dog plasma. J. clin. Invest. 1956, 35, 1025.

5. Moser, H. W., and Emerson, K., Jr. Estimation of the phospholipid phosphorus turnover time in man: Studies in normal individuals, in patients with the nephrotic syndrome and in other types of hyperlipemia. J. clin. Invest. 1955, 34, 1286.

6. Nelson, N. A photometric adaptation of the Somogyi method for the determination of glucose. J. biol. Chem. 1944, 153, 375.

7. Roe, J. H. The determination of sugar in blood and spinal fluid with anthrone reagent. J. biol. Chem. 1955, 212, 335.

8. McCann, W. P., and Jude, J. R. The synthesis of glucose by the kidney. Bull. Johns Hopk. Hosp. 1958, 103, 77.

9. Barker, S. B., and Summerson, W. H. The colorimetric determination of lactic acid in biological material. J. biol. Chem. 1941, 138, 535.

10. Horn, H. D., and Bruns, F. H. Quantitativ Bestimmung von $\mathrm{L}(+)$-Milchsäure mit Milchsauredehydrogenase. Biochim. biophys. Acta 1956, 21, 378.

11. Gordon, R. S., Jr., and Cherkes, A. Unesterified fatty acid in human blood plasma. J. clin. Invest. 1956, 35, 206.

12. Dole, V. P. A relation between non-esterified fatty acids in plasma and the metabolism of glucose. J. clin. Invest. 1956, 35, 150.

13. Van Slyke, D. D., and Neill, J. M. The determination of gases in blood and other solutions by vacuum extraction and manometric measurement. I. J. biol. Chem. 1924, 61, 523.

14. Andres, R., Zierler, K. L., Anderson, H. M., Stainsby, W. N., Cader, G., Ghrayyib, A. S., and Lilienthal, J. L., Jr. Measurement of blood flow and volume in the forearm of man; with notes on the theory of indicator-dilution and on production of turbulence, hemolysis, and vasodilatation by intra-vascular injection. J. clin. Invest. 1954, 33, 482.

15. Somogyi, M. Determination of blood sugar. J. biol. Chem. 1945, 160, 69.

16. Andres, R., Cader, G., Goldman, P., and Zierler, K. L. Net potassium movement between resting muscle and plasma in man in the basal state and during the night. J. clin. Invest. 1957, 36, 723.

17. Gordon, R. S., Jr. Unesterified fatty acid in human blood plasma. II. The transport function of unesterified fatty acid. J. clin. Invest. 1957, 36, 810. 
18. Monod, H., Rohr, D., de Saint-Saens, M., Scherrer, J., and Soula, C. Comparaison du taux normal des constituants sanguins essentiels dans le sang veineux superficiel et profond chez l'homme. J. Physiol. (Paris) 1959, 51, 1011.

19. Butterfield, W. J. H., and Schless, G. Observations on the peripheral metabolism of nonesterified fatty acids. Diabetes 1959, 8, 450.

20. Friedberg, S. J., Klein, R. F., Trout, D. L., Bogdonoff, M. D., and Estes, E. H., Jr. The characteristics of the peripheral transport of $\mathrm{C}^{14}$-labeled palmitic acid. J. clin. Invest. 1960, 39, 1511.

21. Schaeffer, J. P. Morris' Human Anatomy, 11th ed. New York, Blakiston, 1953, p. 774.

22. Roddie, I. C., Shepherd, J. T., and Whelan, R. F. Evidence from venous oxygen saturation measurements that the increase in forearm blood flow during body heating is confined to the skin. J. Physiol. (Lond.) 1956, 134, 444.

23. Coles, D. R., Cooper, K. E., Mottram, R. F., and Occleshaw, J. V. The source of blood samples withdrawn from deep forearm veins via catheters passed upstream from the median cubital vein. J. Physiol. (Lond.) 1958, 142, 323.

24. Stainsby, W. N., Fales, J. T., and Lilienthal, J. L., Jr. Effect of stretch on oxygen consumption of dog skeletal muscle in situ. Bull. Johns Hopk. Hosp. 1956, 99, 249.

25. Cori, C. F. Mammalian carbohydrate metabolism. Physiol. Rev. 1931, 11, 143.

26. Keys, A. The response of the plasma potassium level in man to the administration of epinephrine. Amer. J. Physiol. 1938, 121, 325.

27. Laurell, S., and Christensson, B. Effect of a single dose of some hormones on plasma unesterified fatty acid (UFA). Acta physiol. scand. 1958, 44, 248.

28. DiSalvo, R. J., Bloom, W. L., Brust, A. A., Fergusson, R. W., and Ferris, E. B. A comparison of the metabolic and circulatory effects of epinephrine, nor-epinephrine and insulin hypoglycemia with observations on the influence of autonomic blocking agents. J. clin. Invest. 1956, 35, 568. 